\title{
Vivências de trabalhadores em contexto de precarização: um estudo de caso em serviço de emergência de hospital universitário
}

\section{Experiences of workers in the context of precariousness: case study in the Emergency of University Hospital}

\author{
Nair Monteiro da Silva* \\ Universidade Federal Fluminense - UFF, Niterói, Rio de Janeiro, Brasil \\ Helder Pordeus Muniz** \\ Universidade Federal Fluminense - UFF, Niterói, Rio de Janeiro, Brasil
}

\begin{abstract}
RESUMO
Este artigo apresenta o cotidiano de trabalhadores do Setor de Emergências do Hospital Universitário Antonio Pedro, em Niterói, RJ, destacando suas vivências subjetivas num contexto precarizado. A análise das experiências laborativas foi construída pelo dispositivo da Comunidade Ampliada de Pesquisa, incluindo profissionais de enfermagem e serviço social como sujeitos da produção de conhecimento. A pesquisa focalizou as relações coletivas estabelecidas na equipe e a relação dos trabalhadores com seu trabalho. Observou-se grande dificuldade na construção de ambiente favorável às vivências de prazer e realização profissional decorrentes da política vigente de desmonte do setor, das contratações temporárias de grande parte dos funcionários e do ambiente precarizado, limitando a organização coletiva e o desenvolvimento do ofício. Embora tenham sido detectadas estratégias de construção coletiva do ofício e enfrentamento das condições desfavoráveis do trabalho, inclusive para lidar com o sofrimento, essas dificuldades encaminhavam o sofrimento psíquico no trabalho para uma dimensão patogênica.
\end{abstract}

Palavras-chave: Trabalho hospitalar; Precarização do trabalho; Saúde e trabalho.

\begin{abstract}
This paper presents the daily life of workers at the emergency room of University Hospital Antonio Pedro, Niterói/RJ, highlighting their subjective experiences in a precarious context. The analysis of experiences working device was built by the Community Extended Search including nurses and social service as subjects of knowledge production. The research focused on the relationships established in the collective team and the relationship of workers with their work. We observed a major difficulty in building an environment conducive to experiences of pleasure and professional achievement in the light of existing policy to dismantle the industry, the temporary hires much of the staff and the environment of precarious work, limiting the collective organization and development of the craft. Although strategies of job collective construction and of coping with unfavorable
\end{abstract}


conditions at work have been identified, including dealing with suffering, such difficulties were heading psychological distress at work for a pathogenic size.

Keywords: Hospital work; Precarious employment; Health and work.

\section{Introdução}

O processo de precarização e degradação que vem marcando o ambiente dos hospitais públicos brasileiros atinge profundamente não só os usuários, mas também os profissionais de saúde, sobretudo aqueles que se encontram na linha de frente do sistema (COSTA, 2005; MASSON, 2007; OLIVEIRA, 2009; GODOY, 2009). O objetivo deste artigo é evidenciar as vivências subjetivas dos trabalhadores em sua relação com a precarização do trabalho e as estratégias desenvolvidas para lidar com o sofrimento na construção coletiva de seu ofício.

A pesquisa foi realizada em 2007/2008 com trabalhadores de enfermagem e serviço social do Setor de Emergências do Hospital Universitário Antonio Pedro - Huap, em Niterói, RJ e subsidiou uma dissertação de mestrado (MONTEIRO DA SILVA, 2008). A proposta se encaminhou no sentido de construir com aqueles profissionais um dispositivo metodológico que provocasse debates sobre o trabalho, pois, segundo Schwartz (2007a, p. 36), "para compreender o trabalho, os saberes disciplinares são necessários, mas é com aqueles que trabalham que se validará conjuntamente o que podemos dizer da situação que eles vivem". Apresentamos neste artigo o desenvolvimento e alguns resultados da pesquisa para compreender a relação daqueles trabalhadores com seu ofício.

Antunes (2007) vem afirmando que uma das estratégias para enfrentar a crise do capitalismo tem sido a opção por formas de produção de bens e serviços que levam à exclusão e precarização da força de trabalho humana. Esse movimento internacional do capital é agravado no Brasil (ANTUNES, 2007), já que o receituário neoliberal de diminuição da presença do Estado no atendimento à saúde e educação veio a agravar as condições de trabalho nos setores públicos. O aumento de contratos temporários e o baixo investimento nos equipamentos necessários são alguns dos efeitos mais visíveis dessa política.

Nogueira; Baraldi; Rodrigues (2004) fazem um levantamento das diferentes concepções de precarização presentes em diversos trabalhos acadêmicos e encontram três conceituações de precarização no conjunto dos autores: 1) caracteriza uma situação de déficit ou ausência de direitos de proteção social; 2) decorre de uma instabilidade do vínculo, do ponto de vista dos interesses dos trabalhadores; 3) está associada a condições de trabalho de 
determinados setores da economia que criam vulnerabilidade social para os trabalhadores aí inseridos. Vale à pena salientar que será adotado neste artigo (assim como o foi na pesquisa) o sentido da precarização não apenas em relação às características do contrato de trabalho, mas também à degradação das condições laborativas expressa na falta de instrumentos para se trabalhar adequadamente. A preocupação com os efeitos dessa precarização tem mobilizado sindicatos e pesquisadores, como demonstram as iniciativas de organização do Seminário Nacional de Saúde Mental e Trabalho, ocorrido em São Paulo em 2008, onde foi realizada uma oficina específica sobre saúde mental de trabalhadores da saúde com a participação de pesquisadores e sindicalistas de diferentes regiões do país. O principal tópico das discussões foi a preocupação com a desestruturação dos coletivos de trabalho e com a deficiência das condições de trabalho.

Nesse momento em que são discutidas políticas de humanização no Sistema Único de Saúde - SUS e formas de melhorar a assistência à população, um conjunto de pesquisas, com as quais esta se agrega, vem sendo realizado para investigar como os trabalhadores de saúde têm vivenciado o seu trabalho (COSTA, 2005; MASSON, 2007; OLIVEIRA, 2009; GODOY, 2009). Nesse contexto, além de trabalhos que expliquem porque os serviços públicos de saúde apresentam problemas na assistência, torna-se fundamental explicar como, apesar de todas as dificuldades, ainda existe um mínimo de assistência acontecendo e como esses profissionais enfrentam essas dificuldades.

\section{Abordagens teóricas}

Os referenciais da clínica da atividade e da psicodinâmica do trabalho foram utilizados para analisar a experiência coletiva daquele grupo e o que eles poderiam nos ensinar concretamente sobre seu ofício em meio à complexidade que envolve a dinâmica de um setor de emergências. Esses aportes foram organizados pela perspectiva epistemológica e ética da ergologia, que implica na construção de um dispositivo a três polos. Um primeiro polo envolveria a colaboração de saberes não investidos na atividade, ou seja, as ferramentas teóricas metodológicas dessas duas abordagens clínicas seriam postas em diálogo, de maneira a contribuírem com a análise considerando a riqueza e os limites de cada uma a respeito da atividade, buscandose não estabelecer uma comparação competitiva entre elas, mas uma confrontação pela riqueza da diferença das análises. Durrafourg (1999) afirma a importância de outro polo, o dos saberes investidos na atividade e experiência dos trabalhadores, que viria também colaborar nesse diálogo ao convocar essas abordagens a seu 
requestionamento, evitando a prática de uma mera aplicação de conhecimentos já produzidos. Por fim, um terceiro polo afirmaria os valores fundamentais dessa colaboração e confrontação de saberes, na afirmação de que todos têm o que aprender e a ensinar uns aos outros, e, portanto, uma humildade e um desejo concreto de trabalhar com o outro é fundamental para a concretização do dispositivo.

Esse caminho teórico buscou evidenciar as ações do trabalhador para além da prescrição e dar visibilidade à construção de gestão singular e coletiva de saberes, valores e regras, com a qual esse trabalhador compõe seu trabalho dia após dia (DANIELLOU, 2004). Segundo Schwartz (2007b), trabalhar envolve gerir permanente negociação entre normas antecedentes e renormatizações parciais para alcançar os meios de realizar a tarefa e como exercício para manutenção da saúde. Estando em jogo em toda atividade uma dinâmica que introduz rupturas e descontinuidades a todo momento, a capacidade de desenvolver renormatizações é o que se movimenta em torno da criação.

Dejours (1997) destaca o sofrimento patógeno quando fracassam as estratégias do trabalhador para dar conta de sua atividade e defende a ideia de que o trabalho é operador tanto de saúde e prazer quanto de doença, e, nessa articulação, destaca o homem como construtor de seu campo laborativo e recriador de regras tanto individuais quanto coletivas em face do sofrimento que 0 acomete. A psicodinâmica do trabalho não busca eliminar o sofrimento no trabalho, considerando-o elemento capaz de desencadear transformações laborativas. O sofrimento, nessa perspectiva, pode ser positivo, porque mobiliza para a descoberta de novas estratégias de defesa, a fim de que o indivíduo se possa manter na normalidade. Graças aos avanços da psicodinâmica do trabalho, esse conceito de sofrimento no trabalho move a análise desse mal-estar psíquico para outro registro que não aquele da psicologia individualista e culpabilizante, ampliando-a para um olhar de interrogação frente aos embaraços industriosos. Não há chave universal que possa ser acionada para responder de forma simples ao que acontece nesse espaço de realidade complexa. Qualquer imputação de responsabilidade é sempre parcial, razão pela qual o sofrimento do trabalhador deve ser analisado em situação.

A psicodinâmica do trabalho, ao afirmar que os trabalhadores não são passivos ao sofrimento e constroem sistemas defensivos coletivos para enfrentar os problemas laborativos, traz uma contribuição importante para analisar as incidências psicopatológicas nas situações de trabalho através da distinção conceitual entre 'estratégia defensiva' e 'ideologia defensiva'. Dejours (1994) considera que o foco da psicodinâmica incide mais sobre as estratégias defensivas construídas coletivamente, tendo em vista que, no campo do 
trabalho, o coletivo se sobrepõe ao privado. Essas estratégias se constituem em sistemas pelos quais o trabalhador busca modificar, transformar e minimizar a percepção da realidade laborativa que o faz sofrer. Segundo Dejours (1999) os trabalhadores protegem-se de fatores organizacionais desestabilizantes e/ou potencialmente destrutivos para o aparelho psíquico produzindo normas de condutas defensivas reguladas pelo coletivo de trabalho. Por exemplo, contra a percepção dolorosa da realidade laborativa, a negação é coletivamente produzida, estabelecendo-se um tipo de economia psíquica. Ela funciona porque se sustenta no consenso de um grupo específico de trabalhadores. Porque se apoiam no coletivo, fazem parte do trabalho e contribuem para reorganizá-lo, são modalidades de adequação às pressões, constituindo acordo partilhado pelo grupo. Essa construção coletiva fortalece a coesão do grupo e contribui para a cooperação, com vistas a atender aos objetivos da produtividade. A garantia de sua eficácia depende da participação de todos, e, quando essa defesa não funciona mais, o coletivo pode dissolver-se, com forte impacto sobre a organização real do trabalho. No entanto, embora essas estratégias sejam importantes estabilizadores psíquicos na confrontação do trabalhador com a organização, podem gerar alienação e configurar-se em ideologia. A passagem da estratégia defensiva à ideologia defensiva corresponde ao momento em que se torna um fim em si mesma e para ela convergem todos os esforços no sentido mantê-la e superar tudo o que a poderia desestabilizar.

Clot (2006, p. 116), por sua vez, não trabalha direta nem centralmente com a categoria sofrimento, mas analisa a questão pelo conceito de atividade real, desenvolvido pela clínica da atividade: "a atividade é uma prova subjetiva em que cada um enfrenta a si mesmo e aos outros para ter uma oportunidade de conseguir realizar aquilo que tem a fazer". Por isso o resultado de uma atividade é sempre singular e traz os engajamentos do trabalhador no percurso entre o prescrito e o realizado. Nesse sentido, a atividade realizada é entendida como aquilo que se faz e que se apresenta nos modos operatórios do trabalhador diretamente observáveis, embora signifique parte ínfima do que se pode fazer, sendo, portanto, atualização de uma das atividades possíveis na execução da tarefa. A atividade não traz em si apenas o realizado, mas também as ações suspensas, contrariadas, impedidas ou contra-atividades, que não estão ausentes da vida do trabalho, mas, ao contrário, emergem aí com destaque e precisam ser admitidas na análise. Uma vez que a atividade é também aquilo que não se faz, justifica-se a retomada do conceito de atividade real desenvolvida pela clínica da atividade, que é aquilo que se costuma chamar de atividade por oposição à tarefa, desdobrado por Clot (2006, p. 115) em "atividade realizada e atividade real". Segundo o autor, essas categorias não se correspondem, mas a atividade real traz em si a atividade não 
realizada. A atividade realizada é a que efetivamente pode ser observada, mas ela é apenas uma das possibilidades que se efetivaram. Então o real da atividade inclui também as atividades que não se realizaram. Todo o processo vivenciado pelos trabalhadores envolve debate entre diferentes atividades possíveis, das quais só uma se realiza.

A proposta de Clot (2006) é incluir nesse conceito de atividade os conflitos do real, utilizando os conceitos de atividade contrariada e atividade impedida, em abordagem mais vigotskiana de desenvolvimento. Seguindo de perto Vigotski, Clot (2006) aponta que a atividade possui volume que transborda a atividade realizada, pois, em matéria de atividade, o realizado não possui o monopólio do real. A fadiga, o desgaste violento, o estresse tanto decorrem do fato de não se poder fazer algo quanto daquilo que se faz. Assim, o conceito de atividade deve incorporar o possível ou impossível da atividade a fim de preservar as possibilidades de compreender 0 desenvolvimento e a entrada em sofrimento do trabalhador.

\section{Método e operacionalização da pesquisa}

Segundo Schwartz (2007c) captar a dinâmica dos movimentos que ocorrem nas situações de trabalho é algo que só se pode fazer agregando diferentes abordagens e saberes; por isso realizamos a pesquisa de campo através do dispositivo da Comunidade Ampliada de Pesquisa (BRITO; ATHAYDE, 2003), que tem por proposta produzir olhares diversos sobre o trabalho e a atividade dos trabalhadores, impedindo que as análises se façam de forma isolada e a partir de ponto de vista único. Isso contribui para que outras dimensões estejam presentes, diminuindo o risco de condução dos trabalhos a partir de visão enviesada do assunto. Esse dispositivo foi criado por Brito e Athayde (2003) e implementado inicialmente em parceria com sindicalistas e pesquisadores de diferentes universidades e estados brasileiros (BRITO; ATHAYDE; NEVES, 2003) no Programa de Formação em Saúde, Gênero e Trabalho nas escolas.

Organizamos a investigação em coletivos ad hoc (DEJOURS, 2004), trabalhando simultaneamente um coletivo que atua em campo e outro fora, num trabalho reflexivo ampliado sobre a totalidade da ação em curso. A Comunidade Ampliada de Pesquisa ficou constituída por três coletivos: o de pesquisadores profissionais em campo, o de trabalhadores voluntários do Setor de Emergências do Huap e o de controle (constituído por pesquisadores que não participavam da pesquisa de campo, mas a discutiam com aqueles que participavam), atuando fora do campo de pesquisa. Essa estratégia de um coletivo que não vai a campo possibilita a autoconfrontação do pesquisador 
mediante trabalho reflexivo questionando constantemente sua ação e aprofundando a análise do material extraído da pesquisa.

Inicialmente, em resposta ao convite do chefe de enfermagem da Emergência a um dos pesquisadores para realizar um estudo sobre a relação saúde/trabalho dos profissionais de enfermagem e do serviço social daquele setor, foram realizadas reuniões com os trabalhadores para apresentar-Ihes o projeto de pesquisa, definir seu protocolo, estimular a constituição de um grupo voluntário, discutir a forma de funcionamento dos encontros e esclarecer questões éticas. No transcorrer dessas reuniões o grupo voluntário se formou em torno de dez trabalhadores (de enfermagem e serviço social) e decidiu com os pesquisadores o protocolo desses encontros: 1) os pesquisadores se encarregariam de criar estratégias de mobilização da discussão a partir dos temas escolhidos pelos trabalhadores envolvendo questões trazidas de suas próprias atividades e da atividade de outros trabalhadores do setor; 2) a forma de funcionamento dos encontros deveria ser definida em comum acordo com o grupo, a cada reunião; 3) os encontros seriam mensais, durante os meses de abril a setembro (sendo este último reservado para validação do relatório final de pesquisa), realizados no próprio local de trabalho, no horário de $10 \mathrm{~h}$ as $12 \mathrm{~h} ; 4)$ os pesquisadores utilizariam gravador de voz para registrar os encontros, e o material coletado de uso restrito apenas da equipe e durante a pesquisa. A seguir, negociou-se com o grupo a última fase: a validação do relatório e o fechamento da pesquisa, acertado então para ocorrer um mês após o último encontro, em dia e horário a serem agendados.

O compromisso ético da pesquisa foi nesse momento firmado com os participantes, que têm garantida a liberdade de sair da pesquisa a qualquer tempo que desejar. A metodologia utilizada teve por princípio não expor os voluntários a situação de risco físico, moral e/ou psíquico e contribuiu para preservar a identidade dos participantes, uma vez que o foco da análise recaiu sobre o coletivo daquele Setor de Emergências. $O$ projeto de pesquisa foi encaminhado ao Comitê de Ética do Hospital e aprovado.

Nos encontros buscou-se exercitar uma clínica do trabalho, tendo como base a autoconfrontação do trabalhador com sua atividade, numa dinâmica envolvendo as experiências trazidas pelos trabalhadores e os conceitos utilizados pelos pesquisadores para comentar essas experiências. Os trabalhadores traziam questões que queriam analisar de sua experiência e, em meio ao debate, os pesquisadores faziam intervenções pontuais, trazendo conceitos, colocando perguntas, pedindo esclarecimentos ou esclarecendo eventuais dúvidas. No último encontro, os pesquisadores apresentaram um relatório confeccionado a partir das discussões e das observações efetuadas nos demais encontros. Tal relatório, conforme previamente estabelecido, pôde ser avaliado e discutido 
pelo grupo (que poderia ratificá-lo, retificá-lo, incluir pontos que julgasse omitidos, porém, importantes). Esse foi também o momento do término da pesquisa e da saída dos pesquisadores daquele cotidiano, encerrando-se os trabalhos. Esse diálogo com os trabalhadores mobilizou diferentes forças de convocação (convocação dos saberes) e reconvocação (validação) para se falar sobre a atividade de trabalho. Utilizamos ainda elementos de uma análise temática (MINAYO, 1993) para auxiliar na sistematização que apresentamos aos trabalhadores, como a organização de análise pelos temas mais mobilizadores das discussões.

\section{Descrição geral da situação de trabalho}

Foi em cenário de crise de identidade e precarização das condições de trabalho e de efetivos atravessando o Setor de Emergências do Huap que a pesquisa se processou. O Huap é um hospital universitário e a maior unidade de saúde da cidade de Niterói, considerado na hierarquia do SUS hospital de nível terciário e quaternário em função da alta complexidade de atendimento. No entanto, o funcionamento aberto a todos os casos, sobretudo no Pronto-Socorro, gerava uma série de dificuldades operacionais, agravada principalmente pela superlotação do setor. À época da pesquisa, a Emergência vivia o desafio de atender uma demanda crescente, bem acima de sua capacidade operacional já que a estrutura do hospital mantinha-se praticamente igual a mais de vinte anos. Segundo o chefe da enfermagem da Emergência, as condições de trabalho estavam muito sucateadas, levando o profissional a tentar fazer o melhor numa situação de caos.

Por falta de leitos e de espaço, os pacientes ficavam "internados" em pleno corredor, em observação ou aguardando vaga para entrar nos boxes. "Trabalhamos dentro do possível", destacou o chefe da enfermagem, alegando que sempre foi difícil negociar a saída desses usuários do Setor de Emergências, tanto para fora do hospital quanto, principalmente, para dentro. A transferência tornava-se, assim, um dos nós da Emergência, existindo algumas variáveis para o problema, tais como a gestão inoperante da rede interna e externa e a falta de uma central eficaz de regulação de leitos. Dessa forma, enquanto a transferência não acontecia, os pacientes aguardavam nos boxes, corredores ou sala de Trauma da Emergência. A falta de fluxo desses usuários tornava-se problemática para a ação da Emergência que, de acordo com uma das enfermeiras diaristas, acabava funcionando como enfermaria de pacientes crônicos. $\mathrm{Na}$ visão do chefe da enfermagem seria necessária uma articulação maior daquele setor com os demais setores do hospital para tentar 
minimizar qualquer processo de descontinuidade na assistência, sobrecarregando a Emergência.

As condições gerais de infraestrutura da Emergência refletiam a falta de reformas e investimentos naquele setor, e, consequentemente, o péssimo estado de conservação do prédio e a saturação do espaço físico interferiam no funcionamento dos serviços. A tecnologia precária, com equipamentos em péssimas condições de uso e em quantidade insuficiente, reduzia o conforto dos pacientes, aumentando o esforço dos profissionais. O serviço de limpeza contava com poucos profissionais, oferecendo condições inadequadas de trabalho. Completando o quadro, as reformas previstas para o setor estavam sendo adiadas há aproximadamente cinco anos por falta de recursos.

Referência no atendimento de emergências no Estado do Rio de Janeiro, o Huap buscava soluções que evitassem as filas demoradas e desnecessárias, bem como o fluxo desordenado de pessoas no local. O principal problema da porta de entrada da Emergência consistia na falta de priorização no atendimento ao paciente, já que $75 \%$ dos usuários apresentavam enfermidade de baixa complexidade - nesse sentido, casos mais e menos graves disputavam o atendimento em condições de igualdade. Apesar dessa estatística, de acordo com uma enfermeira da porta de entrada, o problema não se localizava ali, mas na falta de fluxo de saída dos pacientes que chegavam à Emergência e precisavam de internação para seguir o tratamento. Em contrapartida, alguns profissionais destacaram que a falta de resolutividade da equipe também ajudava a 'emperrar' esse fluxo, 0 que apontava para outro ponto frágil do setor: o efetivo de trabalhadores.

O enorme deficit de pessoal afetava diretamente a prestação dos serviços aos usuários, intensificando o trabalho das categorias. Além disso, segundo o chefe da enfermagem, 70\% tinham contrato temporário, só permanecendo no hospital durante dois anos. Em relação às contratações, uma auxiliar de enfermagem destacou que: "a gente está sempre começando; é um desgaste mostrar para os novos a rotina da Emergência". Outra enfermeira completou: "com essa saída do pessoal mais antigo, o ritmo é quebrado; estamos sempre voltando ao ponto de partida".

Também merece destaque a falta de material no setor, influenciando diretamente a qualidade da assistência emergencial. Para uma enfermeira do box, "a falta de material é um obstáculo para a realização do trabalho". E exemplifica: "os lençóis disponíveis não são suficientes nem para o Box".

No entanto, apesar de tamanha precariedade, funcionários e usuários se surpreenderam quando a direção do hospital, em janeiro de 2008, decidiu fechar parcialmente as portas da Emergência, priorizando os casos de urgência/emergência e os procedimentos de alta 
complexidade, restritos a centros especializados e hospitais de ensino. Segundo a direção, essa nova dinâmica não representava o fechamento do setor, mas a adoção de medida de atendimento referenciado por conta não só da impossibilidade de acolher toda a demanda que chegava ao hospital, já superlotado, mas também pela necessidade de adequação do Pronto-Socorro ao perfil vocacional de um hospital universitário. Essa transição, no entanto, deu início ao desmonte da Emergência e, consequentemente, das equipes que ali operavam.

Esse cenário dá ao leitor um parâmetro para entender os debates travados naquele momento e que serão apresentados a seguir, num cruzamento das falas daqueles profissionais acerca de suas vivências laborativas e as dos teóricos selecionados como ferramentas para a condução da pesquisa.

\section{As vivências dos trabalhadores}

Os trabalhadores trouxeram em seus depoimentos a presença de muito sofrimento relacionado com as limitações que encontravam para realizar o trabalho da forma como as regras de seu ofício lhes determinavam. A precariedade produzia sentimentos de impotência como podemos exemplificar nas falas abaixo:

Secando gelo! Uma sensação de não estar fazendo nada
(auxiliar de enfermagem). No dia a dia tive de enfrentar a
realidade da falta de materiais, a impossibilidade de atender
à demanda e o convívio com pessoas com as quais tenho de
brigar (enfermeira diarista). Eu quero é ter recursos para
trabalhar, pois o estresse do dia a dia acaba com a gente
(enfermeira diarista). A tarefa de cuidar dos medicamentos
no box é um estresse, porque nem sempre tem todos os
medicamentos prescritos na farmácia do hospital (enfermeira
do box). Estamos trabalhando em situação de guerra
(assistente social).

Percebemos em conjunto com os trabalhadores que seu sofrimento era profundamente articulado com o impedimento de desenvolver sua atividade, como aborda Clot (2006) ao destacar que uma atividade realizada pode estar, na verdade, se desenvolvendo de forma bastante contrariada, exigindo muito esforço. Ou, em contrapartida, não se estar realizando por encontrar-se totalmente impedida. A questão da atividade contrariada é destacada pelo autor a partir da discussão sobre o gesto impedido, uma característica do modelo taylorista, que provoca sofrimento no trabalhador, que gasta muita energia ao ser impedido de agir.

A noção de atividade contrariada é muito útil para nossa análise, pois aqueles trabalhadores a vivenciavam constantemente ao se queixar 
de não conseguir realizá-la como gostariam, o que gerava desgaste (porque mobilizavam muitos recursos) e insatisfação (porque consideravam que a atividade não fora "bem feita"). Várias eram as situações que propiciavam a atividade impedida, principalmente 0 número excessivo de pacientes e a falta de recursos materiais e humanos para tratá-los. Podemos citar o exemplo dado pelo grupo quanto ao uso improvisado de papelão para substituir o inexistente colar cervical que Ihes permitiria imobilizar o paciente. Em situação de primeiros socorros, utilizavam o material que tinham à mão, adaptando-o a novos usos. Concentrados em sua atividade, buscavam transformar a falta de recursos em ação, pois, em princípio, não é com papelão que se confecciona colar cervical, mas aqueles trabalhadores atribuíram uma nova função a esse material ao ampliar sua utilidade para imobilizar o paciente em situação de socorro emergencial. Assim, diante da falta de recursos, improvisar colar cervical com papelão já estava incorporado àquele gênero profissional. O que se fazia cansativo e causava angústia era a sensação de impotência por não poderem conduzir a atividade de acordo com as prescrições ou da forma como desejariam. Para Clot (2006, p. 122): "Exige-se deles uma espécie de [...] inatividade mais custosa do que a atividade prescrita. Se não pode dissipar-se em ação, essa tensão se impõe como a mais fatigante que existe." Os trabalhadores viam-se tomados por um curso de atividade no qual aquilo que não se podia fazer e o que se desejaria fazer contavam pelo menos tanto quanto aquilo que se fazia. Seus esforços não se resumiam aos despendidos para cuidar do paciente, mas incluíam reprimir sua própria atividade e a dos outros. A atividade contrariada é então fator de desgaste para aqueles trabalhadores porque os impede de fazer o que consideram importante para o paciente e 0 que dá sentido a seu ofício. Quando essa atividade se encontra mais radicalmente interditada, ela pode não se realizar, deixando em seu rastro um desenvolvimento contrariado, provocando tropeços nos efeitos sociais de sua própria dinâmica. Como consequência, os trabalhadores pagam elevado preço como atores desse tipo de dissonância.

É nessa atividade impedida e contrariada que a clínica da atividade se depara com a questão do sofrimento no trabalho. Clot (2006) sugere que o sofrimento se instala porque o poder de agir do trabalhador se encontra diminuído, amputado, impedindo o desenvolvimento da ação laboral. $\mathrm{Na}$ realidade, as condições oferecidas pela própria organização do trabalho acabam estreitando esse poder de agir, uma vez que a simples execução não permite cumprir os objetivos fixados, conforme denuncia a ergonomia. Assim, a atividade realizada já é em si diferente da tarefa oficial prescrita, exigindo do operador acionar recursos próprios para atingir suas metas. O autor, porém, não relega a atividade realizada a segundo plano, pois o realizado 
constitui-se como recurso do real, sendo precisamente no momento em que se realiza a atividade que surgem, por vezes, novas possibilidades que permitem o desenvolvimento do ofício. É nesse sentido que o conhecimento prático construído pelos trabalhadores não deve ser ignorado, pois responde, sobretudo, aos problemas enfrentados no dia a dia de suas atividades.

\title{
6 A morte - do paciente ou do ofício?
}

Basicamente, as dificuldades destacadas mobilizaram a discussão dos trabalhadores para a seguinte questão: como cada um lidava com a morte e o sofrimento dos pacientes num contexto de precariedade das condições de assistência?

\begin{abstract}
A gente vivencia o que é bom e o que é ruim ao mesmo tempo. Morte e vida, a gente vivencia isso o tempo todo (enfermeira do box). Quando trabalhava no repouso via pacientes morrerem quase todos os dias e era preciso tirar aquela 'inhaca' que trazia, tirar a tristeza e voltar à parte prática (auxiliar de enfermagem).
\end{abstract}

Contra o sofrimento, segundo Dejours (1997), o trabalhador pode criar estratégias de defesas individuais e coletivas para dar conta de sua atividade. É nesse sentido que destacamos as estratégias criadas pelos trabalhadores da Emergência para lidar com outro aspecto de sua atividade que pode desencadear sofrimento: a morte do paciente. Esse tema teve repercussão no grupo a partir das questões trazidas em relação à vinculação que com ele se estabelecia durante o período de internação. Para a maioria, o vínculo que se constrói nessa relação pode levar ao adoecimento. Essa questão aponta para uma regra básica daquele ofício e está relacionada diretamente ao gênero profissional: como dosar o envolvimento com o paciente?

Em situação precarizada, o sentido e a importância do trabalho se perdem. E a morte do paciente num trabalho precarizado nos parece ser a marca do impedimento máximo da atividade daqueles trabalhadores que, diante da falta de estrutura, sofriam pela impossibilidade de oferecer ao paciente tudo o que o estado da arte Ihes reservava como alternativas de cuidados. O trabalho impedido em grau extremo dá ao trabalhador a sensação de fracasso por não poder fazer pelo paciente tudo o que entende como necessário dentro do ofício. Nesse sentido, o sofrimento está mais relacionado à morte do ofício. O fato de o paciente morrer em condições mínimas de cuidados faz o trabalhador sentir-se impotente frente à situação de não poder cuidar como deveria. No debate dessa questão verificou-se que a morte do paciente se misturava com o problema do sentido do trabalho tão perdido na situação precarizada daqueles trabalhadores. 
Qual era, entretanto, a forma de cada um lidar com isso? O tema veio à tona quando uma das enfermeiras declarou estar acostumada em seu ofício a ver as pessoas morrendo; então procurava não se abalar ou não aguentaria. Quando foi trabalhar no box da Emergência, percebeu que a equipe de lá criava vínculo com os pacientes, o que ela considerava perigoso, porque, quando o paciente morria, todos ficavam tristes. O grupo então abordou o assunto, destacando 0 seguinte:

\begin{abstract}
Quando você se joga muito, você sofre muito; e, se você sofre muito, você adoece (enfermeira do box). No Trauma nosso relacionamento com o paciente é diferente dos outros setores, pois ele não fica tempo suficiente para a gente saber dele (enfermeira do Trauma). Mas tem pacientes que a gente gostaria de saber como ficou a situação no hospital (enfermeira do box). Aqui não consigo ter uma interação maior com o paciente, como tinha, por exemplo, quando estava no box, porque saía e no dia seguinte encontrava o paciente lá (enfermeira do Trauma). Mas agradeço por não ter esse contato maior com o paciente e criar vínculos, porque, se o paciente morre, é difícil (enfermeira plantonista do Trauma).
\end{abstract}

Embora a questão afligisse a todos, as posições destacadas revelavam a forma como cada um lidava com o tema e as estratégias criadas para evitar o sofrimento: "A gente vai aprendendo com a experiência a ser mais racional, a não chorar pela morte do paciente como se fosse um parente" (auxiliar de enfermagem). Uma enfermeira do box afirmou: "Eu não crio vínculos, crio relações." E esclarece sua estratégia em diferenciar vínculo pessoal e vínculo profissional: "Vínculo é quando a pessoa carrega os problemas do paciente para casa, quando não consegue se desligar deles fora do hospital." Outras enfermeiras destacaram: "Eu não crio vínculos, crio amizade." "Existe diferença entre as pessoas, e eu não consigo desligar." "É importante desligar o botãozinho." A esta última, o grupo pediu que ensinasse como desligar o botãozinho, e ela completou: "É preciso achar um meio-termo, pois há pacientes com os quais ocorre um apego maior, e achar esse botãozinho é tudo."

A enfermeira que diferenciava vínculo e relacionamento, preocupada em parecer desumana para o grupo, argumentou: "Eu não sou desumana. Diante da falta de estrutura, dou o meu melhor, mas doso meu envolvimento com o paciente." Um enfermeiro apresenta outro ponto de vista: "Quando entrei, a moda era fazer vínculo, e eu não sabia bem o que significava essa palavra, mas hoje também penso que fazer vínculo é fazer o melhor possível."

$\mathrm{O}$ que inicialmente parece paradoxal nesses fragmentos, longe de ser absurdo, revela um sistema coerente de construção coletiva visando ao controle de outros sofrimentos ocasionados pelo contato com a dor 
e a morte do paciente. Segundo Dejours (1994), a regulação do sofrimento constitui a possibilidade de adaptação à organização por meio da utilização de estratégias defensivas individuais ou coletivas que levem ao abrandamento da percepção da realidade de trabalho. Quando essas estratégias fracassam, abre-se espaço para o adoecimento. A fim de darem conta do prescrito, corresponderem às expectativas da organização e não adoecerem, os trabalhadores utilizavam estratégias de enfrentamento - conformismo, individualismo, negação de perigo, agressividade, passividade, entre outras - que os protegiam das situações causadoras do sofrimento e mantinham seu equilíbrio psíquico.

Outro problema, porém, afetava essa relação. Os trabalhadores reconheciam que não havia tempo suficiente para estabelecer melhor comunicação com o paciente. Uma enfermeira declarou que para se comunicar melhor com o paciente e seus acompanhantes era preciso que ela tivesse uma equipe, porque era precário o apoio coletivo. Um dos principais problemas nesse sentido era o fato de a maioria da equipe ser composta por temporários, contratados para atuar no hospital por apenas dois anos. Se para a cooperação no trabalho (DEJ OURS, 1993) é necessário estabelecer relações de confiança no cumprimento de regras de trabalho construídas em comum, e se isso necessita de tempo e investimento, como lidar com o fato de que a troca de grande parte da equipe a cada dois anos obrigava o coletivo a enfrentar novo trabalho de reconstrução?

É por essa via que Clot (2006), por sua vez, vai verificar que quando os trabalhadores começam a ter tempo de conversar é possível o debate dentro do gênero para as constantes renormatizações. Esses debates se constituem em meios facilitadores para a migração de vivências individuais ao coletivo, possibilitando ao trabalhador reinterpretar suas ações. Para Clot (2006, p. 41) "um gênero vincula entre si os que participam de uma situação [...] é como uma senha conhecida apenas por aqueles que pertencem ao mesmo horizonte social e profissional".

O conhecimento do trabalhador a respeito de sua atividade é elemento-chave para a compreensão de seu trabalho. Esse saber fazer tem por base um processo de elaboração individual e coletiva que forma um conjunto de técnicas e enunciados pronto para ser acionado pelo coletivo; uma espécie de memória. O debate permite que as invenções individuais possam migrar para esse acervo coletivo numa espécie de validação que protege o trabalhador em sua atividade.

Os conflitos apontados pelos trabalhadores da Emergência causam a impressão de que eles se encontravam aparentemente sozinhos em sua ação, abandonados à própria sorte, embora, na verdade, estivessem em meio a um debate de normas com as demais atividades para gerir a sua própria. Isso ocorria tanto porque as 
normas prescritas pela organização eram insuficientes quanto porque as normas antecedentes informais também não estavam vigorando naquele momento. E para que renormatizações parciais se tornem ferramentas de trabalho é preciso que sejam validadas pelos trabalhadores, ou seja, para garantir a continuidade da assistência, esse coletivo precisaria dialogar constantemente sobre suas formas de fazer, agregando essas ferramentas ao patrimônio já existente de normas e regras coletivas de trabalho e praticando-as como formas alternativas de realizar a atividade.

\title{
7 O fechamento da Emergência como perspectiva de análise de outro problema: a falta de protagonismo e de autonomia no trabalho
}

Os trabalhadores muito se queixavam do excesso de demanda de paciente, o que creditavam ao fato de a Emergência estar em funcionamento aberto; quando, porém, a direção fechou parcialmente o setor e o hospital passou a só aceitar pacientes referenciados, eles descobriram que continuavam com excesso de trabalho porque não têm autonomia para decidir a política de entrada e saída de pacientes daquela unidade. O próprio fechamento parcial da Emergência foi vivenciado como medida autoritária da direção. Essa ausência de possibilidade de decidir sobre aspectos essenciais da assistência aparece como falta de reconhecimento de sua capacidade de contribuir para decisões quanto à organização do trabalho, como expressaram:

\begin{abstract}
As dificuldades não vão diminuir porque as decisões vão continuar sendo tomadas de cima para baixo (enfermeira plantonista do Box). A demanda não vai diminuir porque a Emergência está fechada. Ao contrário, ela continua cheia, pois estão mandando pacientes lá de cima para cá (enfermeira diarista). É uma Emergência parcialmente fechada (assistente social). Um simples telefonema da direção tira a vaga de um paciente grave na Emergência ou leva o paciente daqui para ser atendido em outro setor, tirando a vaga de alguém de lá (enfermeira do box). É porque alguém lá de cima acha que o paciente será mais bem atendido lá, principalmente se o paciente que tem QI reclamar da Emergência (assistente social). E o que faz a direção pensar que a Emergência não tem suporte à altura para solucionar o problema do paciente? Então ele vai ter o problema solucionado porque tem mais QI? E os outros? (plantonista do Trauma).
\end{abstract}

Essa falta de reconhecimento do direito dos trabalhadores à contribuição assim como das estratégias utilizadas pelos 
trabalhadores para dar conta da precariedade dificulta a produção de sentido, que poderia gerar prazer no trabalho, levando a um encaminhamento patógeno do sofrimento.

\section{Considerações finais}

A precarização do trabalho na Emergência do Huap era vivenciada pelos trabalhadores através de diferentes estratégias defensivas para dar conta do sofrimento de trabalhar naquele setor. O sofrimento maior não se devia ao fato de lidarem com a morte e a doença, mas, antes, por compreenderem que não dispunham dos meios necessários para cuidar dos pacientes. Esse impedimento da atividade os obrigava a dar 'jeitinhos' e a trabalhar com a precariedade. Ver os pacientes falecerem ou piorarem em meio à falta de recursos foi problemática bastante presente em suas falas, 0 que nos leva a reconhecer que existem limites nessas formas astuciosas de lidar com um ambiente precarizado e sobre o qual se tem pequena margem de controle para interferir. Por mais que os trabalhadores procurassem gerenciar seu dia a dia nesse ambiente, os índices de rotatividade e absenteísmo do setor apontam para inconsistência na comunicação e na forma de a organização compreender as atividades humanas no trabalho.

Encontramos ressonâncias dessas questões na pesquisa de Oliveira (2009) que, ao adotar como objeto de estudo o processo de adoecimento da enfermagem no pronto socorro de um hospital universitário no Rio Grande do Sul, descreve que as transformações que estão ocorrendo nos hospitais - sejam tecnológicas, sejam organizacionais com as políticas de flexibilização do trabalho - estão produzindo adoecimento pela margem de manobra dos trabalhadores frente a esse sofrimento ser bastante reduzida. Conclui que a via do sofrimento patogênico é a predominante já que não é possível a criação e autonomia no trabalho que possibilitariam a construção do prazer.

Nas conversas com os trabalhadores, um ano depois de finalizada a pesquisa de campo, tivemos ciência de que alguns trabalhadores haviam tirado licenças relativas a problemas psicológicos e doenças psicossomáticas, como gastrite. Isso sugere alguma dificuldade na construção e manutenção de estratégias coletivas de defesa para evitar as descompensações psicossomáticas. Além disso, muitos dos profissionais que passam em concurso público nem sempre assumem, o que demonstra quão pouco atrativa está sendo a carreira no hospital, e, infelizmente, aponta para a continuidade de problemas na assistência e de adoecimento dos trabalhadores. Godoy (2009), ao abordar o prazer e o sofrimento do enfermeiro na relação com o trabalho num hospital de urgência e emergência de Belo Horizonte, 
afirma que uma das principais fontes de insatisfação é a rotatividade de pessoal, já que o quadro de profissionais é composto em sua maioria por trabalhadores com contratos administrativos, diminuindo constantemente $\mathrm{o}$ número de funcionários efetivos. A falta de capacitação e treinamento do pessoal recém-admitido e a falta qualitativa e quantitativa de insumos materiais imprescindíveis para o trabalho produzem lentidão na assistência, obrigando os trabalhadores a improvisar, criando quebra-galhos e macetes para conseguir cuidar do paciente, apesar de tudo.

Nas andanças pelo Setor de Emergências foi possível perceber a complexidade da assistência ao paciente em situação emergencial e observar que a atividade resultava da dinâmica entre a variabilidade organizacional (incluindo dificuldades para realização de exames, falta de vagas e de materiais, etc.), a variabilidade presente no próprio SUS e as regulações que os profissionais desenvolviam para dar conta de suas metas, cujo conjunto compõe a assistência ao paciente envolvendo seu estado clínico, seu modo de viver a internação, suas condições de vida e trabalho, sua família ou acompanhante, etc. Esse tema possibilitou então discutir o trabalhador na coletividade, sendo ponto de partida para compreender como vivenciavam os desafios impostos pela organização. Naquele setor, diferentes categorias profissionais buscavam regular tanto as dificuldades organizacionais oriundas do próprio hospital como os problemas advindos do SUS para garantir a continuidade da assistência.

Esta pesquisa contribuiu para afirmar a necessidade de continuar os estudos sobre a saúde do trabalhador a partir de suas formas de resistência e luta nas tramas intersubjetivas do trabalho. Por outro lado percebe-se, a partir dos diálogos com as outras pesquisas realizadas, que um dos limites deste trabalho foi a não consideração das relações de gênero na análise, bem como um melhor aprofundamento das relações com os médicos. A pesquisa de Masson (2007) traz uma preciosa contribuição ao afirmar que a criatividade coletiva auxilia na produção de sentido para o trabalho, mas a invisibilidade produzida pela divisão social e sexual do trabalho, com as suas marcações de gênero e de classe, pode debilitar esse patrimônio coletivo fazendo com que não sejam apenas os trabalhadores que estejam em risco, mas o próprio ofício. Assim, outro veio fecundo a ser percorrido para futuras pesquisas sobre o trabalho coletivo em serviços de saúde pública seria compreender melhor como se processa a história macro e micro dos ofícios de saúde, articulada à divisão social e sexual do trabalho. 


\section{Referências}

ANTUNES, R. Dimensão da precarização estrutural do trabalho. In: DRUCK, G; FRANCO, T. (Orgs.). A perda da razão social do trabalho: terceirização e precarização. São Paulo: Boitempo, 2007. p. 13-22.

BRITO, J.; ATHAYDE, M. Trabalho, educação e saúde: o ponto de vista enigmático da atividade. Revista Educação, Saúde e Trabalho, v. 1, n. 2, p. 63-89, 2003.

BRITO, J.; ATHAYDE, M.; NEVES, M. Y. Caderno de métodos: programa de formação em saúde, gênero e trabalho nas escolas. J oão Pessoa: Editora Universitária da UFPB, 2003.

CLOT, Y. A função psicológica do trabalho. Petrópolis: Vozes, 2006.

COSTA, A. L. R. C. As múltiplas formas de violência no trabalho de enfermagem: o cotidiano de trabalho no setor de emergência e urgência clínica em um hospital público. 2005. 268f. Tese (Doutorado em Enfermagem) - Escola de Enfermagem de Ribeirão Preto, Universidade de São Paulo, Ribeirão Preto, 2005.

DANIELLOU, F. Introdução: Questões epistemológicas acerca da ergonomia. In: DANIELLOU, F. (Coord.). A ergonomia em busca de seus princípios: debates epistemológicos. São Paulo: Ed. Edgard Blücher, 2004, p. 1-18.

DEJOURS, C. Inteligência operária e organização do trabalho: a propósito do modelo japonês de produção. In: HIRATA, H. (Org.). Sobre o modelo japonês. Automatização, novas formas de organização e de relações de trabalho. São Paulo: Edusp, 1993. p. 280-309.

A carga psíquica do trabalho. In: BETIOL, M. I. S. (Org.). Psicodinâmica do trabalho - contribuições da escola dejouriana à análise da relação prazer, sofrimento e trabalho. São Paulo: Editora Atlas, 1994. p. 21-32.

Vargas, 1997.

O fator humano. Rio de Janeiro: Editora Fundação Getúlio

A banalização da injustiça social. Rio de Janeiro: Fundação Getúlio Vargas, 1999.

. Subjetividade, trabalho e ação. Revista Produção, v. 14, n. 3, p. 27-34, set./dez. 2004.

DURAFOURG, J. Assembler les pièces du puzzle. Territoires du travail, n. 3, p. 71-78, maio 1999.

GODOY, S. C. B. Prazer e sofrimento do enfermeiro na relação com o trabalho: estudo em um hospital de urgência e emergência de Belo Horizonte. 2009. 188f. Tese (Doutorado em Enfermagem) Escola de Enfermagem, Universidade Federal de Minas Gerais, Belo Horizonte, 2009. 
MASSON, L. P. A dimensão relacional do trabalho de auxiliares de enfermagem de Unidade Neonatal: uma análise do ponto de vista da atividade. 2007. 236f. Dissertação (Mestrado em Saúde Pública) - Escola Nacional de Saúde Pública, Fundação Oswaldo Cruz, Rio de Janeiro, 2007.

MINAYO, M. C. S. O desafio do cotidiano: pesquisa qualitativa em saúde. 2.ed. São Paulo; Rio de Janeiro: Hucitec-Abrasco, 1993.

MONTEIRO DA SILVA, N. Setor de emergência: modos de trabalhar nas interfaces de um cotidiano hospitalar. 2008. 173f. Dissertação (Mestrado em Psicologia), Universidade Federal Fluminense, Niterói, 2008.

NOGUEIRA, R. P.; BARALDI, S.; RODRIGUES, V. A. Limites críticos das noções de precariedade e de precarização do trabalho na administração pública. In: BARROS, A. F. R.; SANTANA, J. P.; SANTOS NETO, P. M. (Orgs.). Observatório de Recursos Humanos em Saúde no Brasil. Estudos e Análises - Vol. 2. Brasília: Ministério da Saúde, 2004. p. 81-103.

OLIVEIRA, N. T. O processo de adoecimento do trabalhador da saúde: o setor de enfermagem do pronto socorro de um hospital universitário. 2009. 148f. Tese (Doutorado em Serviço Social) Faculdade de Serviço Social, Pontifícia Universidade Católica do Rio Grande do Sul, Porto Alegre, 2009.

SCHWARTZ, Y. Trabalho e ergologia. In: SCHWARTZ, Y.; DURRIVE, L. (Orgs.). Trabalho e ergologia: conversas sobre a atividade humana. Niterói: Eduff Editora, 2007a, p. 25-36.

Trabalho e uso de si. In: SCHWARTZ, Y.; DURRIVE, L.

(Örgs.). Trabalho e ergologia: conversas sobre a atividade humana. Niterói: Eduff Editora, 2007b. p. 191-206.

DÜRRIVE, L. (Orgs.). Trabalho e ergologia: conversas sobre a atividade humana. Niterói: Eduff Editora, 2007c, p. 249-275.

\section{Endereço para correspondência \\ Nair Monteiro da Silva}

Nucleo de Estudos e Intervenções em Trabalho, Subjetividade e Saúde, Campus do Gragoatá, Rua Professor Marcos Waldemar de Freitas Reis, Bloco O, Departamento de Psicologia, São Domingos, CEP 24210-201, Niterói - RJ, Brasil

Endereço eletrônico: nizamonteiro@gmail.com

Hélder Pordeus Muniz

Departamento de Psicologia UFF, Núcleo de Estudos e Intervenções em Trabalho, Subjetividade e Saúde, Rua Professor Marcos Waldemar de Freitas Reis, Bloco O, Departamento de Psicologia, São Domingos, CEP 24210-201, Niterói - RJ, Brasil Endereço eletrônico: heldermuniz@uol.com.br 
Nair Monteiro da Silva, Helder Pordeus Muniz Vivências de trabalhadores em contexto de precarização

Recebido em: 02/08/2010

Reformulado em: 23/09/2010

Aceito para publicação em: 27/09/2010

Acompanhamento do processo editorial: Deise Mancebo

\section{Notas}

* Mestre em Psicologia pela Universidade Federal Fluminense - UFF.

** Professor do Departamento e do Programa de Pós-Graduação em Psicologia da UFF. 